\section{NOVA TELLVS}

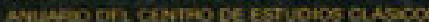

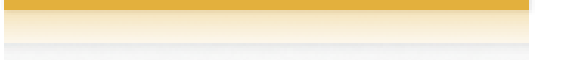

$\uparrow$
Nova Tellus

ISSN: 0185-3058

novatelu@servidor.unam.mx

Centro de Estudios Clásicos

México

Valdés García, María Alejandra

La etopeya en Basilio de Cesarea

Nova Tellus, vol. 26, núm. 2, 2008, pp. 179-200

Centro de Estudios Clásicos

Distrito Federal, México

Disponible en: http://www.redalyc.org/articulo.oa?id=59115497008

- Cómo citar el artículo

- Número completo

- Más información del artículo

Página de la revista en redalyc.org

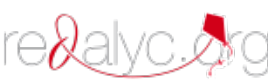

Sistema de Información Científica

Red de Revistas Científicas de América Latina, el Caribe, España y Portugal

Proyecto académico sin fines de lucro, desarrollado bajo la iniciativa de acceso abierto 


\title{
La etopeya en Basilio de Cesarea
}

\author{
María Alejandra VALDÉs GARCíA \\ Universidad Nacional Autónoma de México \\ malva@correo.filos.unam.mx
}

RESUMEN: La etopeya es uno de los ejercicios preparatorios o progymnásmata que concernían a la educación del rétor. Es considerado uno de los ejercicios más complejos, ya que su elaboración consistía en hacer una alocución apropiada a un personaje determinado para la cual debían tomarse en cuenta distintos aspectos, entre ellos el carácter del personaje y la situación en que éste se encontraba. El objetivo de esta comunicación es analizar su aplicación en algunas piezas de la producción oratoria de Basilio de Cesarea.

\section{$* * *$}

ABSTRACT: The ethopoiia is one of the preliminary rhetorical exercises or progymnásmata that made up the training of the rhetor. This is one of the most complex exercises, as its implementation consisted in delivering an allocution befitting to a given addressee: in order for this to be done several aspects had to be taken into account, among which the character of the addressee and the situation where he/ she stood. The scope of this article is, then, to survey use of ethopoiia in some of the religious discourses written by Basil from Caesarea.

PAlABRAS ClAVE: Basilio de Cesarea, etopeya, paideia, patrología, progymnásmata, retórica.

RECEPCIÓN: 30 de junio de 2008.

ACEPTACIÓN: 4 de octubre de 2008. 


\title{
La etopeya en Basilio de Cesarea ${ }^{1}$
}

\author{
María Alejandra VALDÉs GARCÍA
}

Uno de los ejercicios preparatorios o progymnásmata más complejos es la etopeya. ${ }^{2}$ El ejercicio consistía en elaborar una declamación de acuerdo al carácter de un personaje en una situación determinada, ${ }^{3}$ y la composición era provocada por

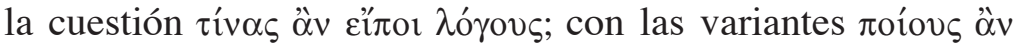

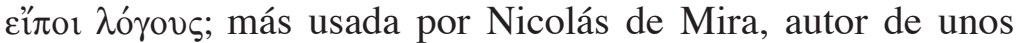

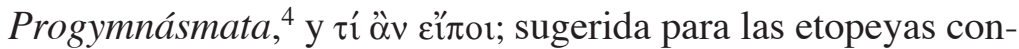

\footnotetext{
${ }^{1}$ Esta comunicación fue presentada en el XVI Encuentro de la International Society for the History of Rhetoric (ISHR), llevado a cabo en Estrasburgo, Francia, del 24 al 29 de julio de 2007, y se encuadra en los siguientes proyectos de investigación de la Universidad de Salamanca: "La escuela griega: pensum, métodos e influencia" (HUM2007-62093/FILO), subvencionado por el Ministerio de Educación y Cultura, y "El sistema de enseñanza en la antigua Grecia y su influencia en la literatura" (SA049A05), por la Junta de Castilla y León.

${ }^{2}$ Nos referiremos a este recurso con el nombre general de etopeya ( $\dot{\eta} \theta$ o alocución de un personaje), si bien, es sabido que se le denomina con nombre más preciso como prosopopeya ( $\pi \rho \circ \sigma \omega \pi$ олой $\alpha$ ), cuando se da voz a objetos o animales, e idolopeya ( $\varepsilon i \delta \omega \lambda$ oлouí $\alpha$ ) cuando el parlamento es expresado por un difunto. Demetr., Eloc., 265, es el primero que registra el término "etopeya" dentro de la historia de la teoría retórica. Quint., Inst., 3, 8, 49, también usa esta única denominación para el recurso, aunque en ella se engloban los tres tipos de alocución: etopeya, prosopopeya e idolopeya. Nicol., Prog., 65, afirma que también es denominada ṕn一øı. Sobre la etopeya: Theo, Prog., 115-118; Hermog., Prog., 20-22; Aphth., Prog., 34-36; Nicol., Prog., 63-67; Lib., Prog., 361-437; Quint., Inst., 3, $8,49-54$ y $9,2,29-37,58$

${ }^{3}$ El carácter del hablante consta entre las pruebas de persuasión mediante el discurso, cf. Arist., Rh., 1365 a 1-19. La Rh. Al., 1434 b únicamente aconseja procurar que el carácter se acomode a las personas, analizando los distintos caracteres para lograr un discurso expresivo, pero no desarrolla los aspectos de la etopeya.

${ }^{4}$ Los autores de Progymnásmata que consultamos para esta exposición son los de Teón de Alejandría, Hermógenes de Tarso, Aftonio de Antioquía y Nicolás de
}

NOVA TELLVS, 26•2, 2008 
tenidas en el libro IX de la Anthologia Palatina. ${ }^{5}$ Dentro del discurso, la transición a esta figura no precisa de una introducción formal; Quintiliano apunta que es suficiente variar el tono de la voz, ${ }^{6}$ pero en las etopeyas halladas en las homilías de Basilio de Cesarea, el autor en quien se centra nuestra atención, es poco frecuente que no aparezca la frase que preludia o sucede a la alocución. ${ }^{7}$

La complejidad de este ejercicio, considerado por algunos como el ejercicio escolar por excelencia, ${ }^{8}$ radica en que deben tenerse en cuenta diversos aspectos: la condición del personaje, el tipo de elocución apropiada a éste, la circunstancia en que se encuentra e incluso el auditorio al que va dirigida. ${ }^{9} \mathrm{El}$ personaje, en primer lugar, puede ser determinado ( $\dot{\omega} \rho ๘ \mu \varepsilon \dot{v} \vee \varsigma)$ o indeter-

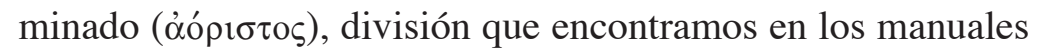
de ejercicios preparatorios de Teón de Alejandría y Hermógenes de Tarso, pero no en los de otros rétores. Hermógenes clasifica de manera precisa al personaje determinado en su obra $D e$ statibus. De acuerdo con su clasificación, éstos pueden ser, en el orden enunciado, los definidos por un nombre propio, como Pericles o Demóstenes; por correlativos, como padre, hijo, esclavo o profesor; por nombres infamantes, tales como miserables, adúlteros, aduladores; por nombres éticos, como campesinos o glotones; por combinación de dos apelativos, como hombre rico joven; o por combinación de persona y hecho, como un hombre joven maquillado acusado de prostitución, y

Mira en las siguientes ediciones: M. Patillon-G. Bolognesi (eds.), 1997; H. Rabe (ed.), 1913; H. Rabe (ed.), 1926; I. Felten (ed.), 1913. Las traducciones castellanas corresponden a Ma. D. Reche Martínez, 1991. Las de Nicolás son propias.

${ }^{5}$ Cf. J. L. Fournet, 1992, p. 255.

${ }^{6}$ Quint., Inst., 1, 8, 3: “... esse tamen flexum quondam, quo distinguantur ab iis, in quibus poeta persona sua utetur".

${ }^{7}$ Para S. K. Stowers, 2003, pp. 351-369, el apóstrofe es una de sus formas de introducción.

${ }^{8}$ G. L. Kustas, 1970, p. 59.

${ }^{9}$ Hermog., Prog., 21. Sobre la dificultad de este progýmnasma, cf. Quint., Inst., $3,8,49$. 
por último los designados por simples apelativos, como general, orador, etcétera. ${ }^{10}$

De acuerdo con esto, la mayoría de los personajes pueden ser definidos, puesto que generalmente se les caracteriza, si no con un nombre propio, con algún calificativo, ${ }^{11}$ salvo que, en palabras de Hermógenes, se haga referencia a él llanamente con un $\tau$ ò $\tau$ í.. ${ }^{12}$

A la caracterización del personaje, además de su definición, también contribuyen sus acciones, las cuales suelen ser narradas en distintas partes del discurso. Aunque estos ámbitos pertenecen generalmente a la descripción y al relato, su manera de proceder ante las circunstancias proporciona pistas sobre su personalidad, lo que de alguna manera va predisponiendo al oyente, cuyo carácter también hay que tener en cuenta en el momento en que se produce la etopeya. ${ }^{13}$ Cada situación debe contar con una elocución adecuada, al decir de Teón:

No se hable sobre hechos importantes de un modo humilde, ni sobre hechos insignificantes de un modo sublime, ni sobre hechos vulgares de un modo grave, ni sobre hechos terribles de un modo relajado, ni sobre hechos vergonzosos de un modo atrevido, ni sobre hechos lamentables de un modo afectado, sino que se debe proporcionar a cada uno de los hechos la elocución adecuada, buscando al mismo tiempo lo que cuadra bien al personaje, al modo, al tiempo, a la fortuna y a cada uno de los elementos antes mencionados. ${ }^{14}$

\footnotetext{
${ }^{10}$ Cf. Hermog., Stat., 1, 25-48. Esta clasificación de personajes guarda cierto parecido con la enumeración de Theo, Prog., 115-116.

${ }^{11}$ Cf. R. Blondell, 2004, p. 54.

12 Sobre los personajes indeterminados Quint., Inst., 9, 2, 36 propone: "hic aliquis" et "dicat aliquis", lo que es posible en caso de réplicas anónimas, pero también afirma en 9,2, 32 que es imposible imaginar un discurso sin imaginar la persona a quien pertenece. Para el caso de personajes "indeterminados" relativos a etopeyas colectivas, cf. I. J. F. de Jong, 1987.

${ }^{13}$ Theo, Prog., 115; Nicol., Prog., 64.

${ }^{14}$ Ibidem, trad. de Ma. D. Reche Martínez, 1991; cf. Arist., Rh., 1408 a 10 ss., y Hermog., Id., 368-380.
} 
Otro criterio de clasificación de la etopeya, proporcionado únicamente por Hermógenes, es el considerarla simple ( $\dot{\alpha} \pi \lambda \eta \dot{n})$ o doble $(\delta i \pi \lambda \eta ́) .{ }^{15}$ Se habla de una alocución simple cuando se presenta a alguien hablando consigo mismo, en cuyo caso se produce un monólogo o, de manera más personal, una reflexión, ${ }^{16}$ y de etopeya doble cuando el personaje habla con otro, es decir, cuando se implica a más de un personaje, en cuyo caso se producen el discurso directo o el diálogo. ${ }^{17}$ Citamos los ejemplos proporcionados por Hermógenes:

(Hablando) consigo mismo, por ejemplo: “¿qué palabras diría un general al regresar de la victoria?"; con otros, por ejemplo: "¿qué palabras dirigiría un general a su ejército después de la victoria?"18

Entre las distintas clases de etopeya los rétores distinguen

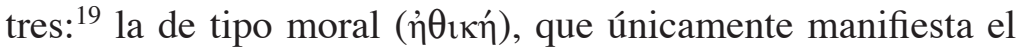
carácter del personaje, ${ }^{20}$ como en el ejemplo propuesto por Aftonio: "¿Qué palabras pronunciaría un hombre del interior al ver por primera vez el mar?"; emotiva ( $\pi \alpha \theta \eta \tau 1 \kappa \eta ́)$, si transmite ante todo emoción: ${ }^{21}$ "¿Qué palabras pronunciaría Hécuba

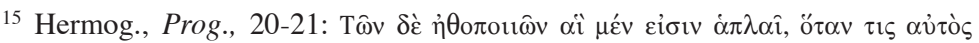

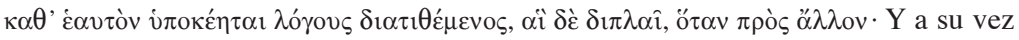

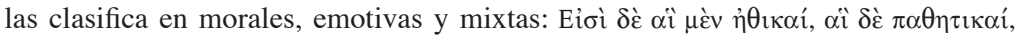

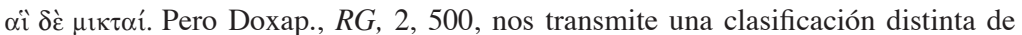
Geometres muy aproximada a la del lugar común: es una etopeya simple cuando se trata de un personaje de este tipo: un campesino, un orador, etcétera, pero etopeya compuesta cuando quien habla es un padre que es a la vez agricultor.

${ }^{16}$ Entendida como deliberación con uno mismo. Sobre este asunto, cf. Ch. Perelman \& L. Olbrechts-Tyteca, 20005 , pp. 85-91.

${ }^{17}$ Cf. Theo, Prog., 60, y Hermog., Prog., 20-21. Cf. Theo, Prog., 89. Este tipo de narración preludia el ejercicio más avanzado de la etopeya. Dentro de la retórica latina contamos con un ejemplo de diálogo (sermocinatio) relacionado con el personaje y su carácter en Auct. ad Her., 4, 52, 65.

${ }^{18}$ Hermog., Prog., 20-21.

${ }^{19}$ Cf. cuadro p. 197.

${ }^{20}$ Acerca de la caracterización y la etopeya, cf. J. Ureña Bracero, 2000.

${ }^{21}$ Para Quint., Inst., 6, 2, 12, entre $\hat{\eta} \theta_{0} \varsigma$ y $\pi \alpha \dot{\theta} \theta$ o existe una diferencia de gradación.
} 
cuando Troya yacía vencida?", y mixta ( $\mu$ $\kappa \tau \eta ́)$, la resultante de una combinación de ambos tipos, reflejando a la vez carácter y emoción: ${ }^{22}$ "¿Qué palabras pronunciaría Aquiles ante el cadáver de Patroclo mientras se decidía a combatir?"23 Las etopeyas emotivas mejor logradas de Basilio son, a juicio de J. M. Campbell, las encontradas en sus homilías a los mártires. $^{24}$

La elaboración aconsejada por los rétores para este ejercicio es diversa. Teón difiere del resto de los progimnasmatistas en sus recomendaciones, pues prescribe hacerla a manera de argumentación, considerando más bien la clase de acción de que se va a ocupar, que el punto de vista temporal, como sugieren los demás tratadistas. Concretamente enumera diferentes topoi según se trate de un discurso de exhortación, petición, consolación o disculpa, ${ }^{25}$ aunque al final del apartado dedicado a este ejercicio sugiere que, para elaborar las prosopopeyas de manera más exacta y compleja, se recurra a los lugares de argumentación mencionados en el ejercicio preparatorio de la thesis. ${ }^{26}$ Los demás rétores coinciden en que la elaboración debe hacerse siguiendo los tres tiempos: presente, pasado y

\footnotetext{
22 Theo, Prog., 117; Hermog., Prog., 21; Aphth., Prog., 35; Nicol., Prog., 64.

${ }^{23}$ Aphth., Prog., 35. En cuanto a la relación del personaje con el tipo de etopeya, M. V. Pérez Custodio, 1997, p. 804, hace una apreciación interesante: las etopeyas patéticas son protagonizadas por personajes femeninos, las de personajes genéricos e indeterminados se consideran éticas y las expresadas por un personaje masculino definido pertenecen al tipo mixto.

${ }^{24}$ J. M. Campbell, 1922, p. 58. Los discursos de proceso y despedida de las homilías a los mártires entran en este género de etopeya: Homilia in Iulittam martyrem: Proceso ( $P G$ 31, $240 \mathrm{~B})$ y discurso de despedida ( $P G$ 31, $241 \mathrm{~A})$; Homilia in martyrem Gordium: Proceso $(P G 31,500 \mathrm{~A}-501 \mathrm{~A})$ y discurso de despedida ( $P G$ 31, 501 C-505 C); Homilia in XL martyres sebastenses: Proceso ( $P G 31,512$ B-513 C) y discurso de despedida ( $P G 31,517$ A-520 A).

${ }^{25}$ Cf. Quint., Inst., 3, 4, 3; 3, 8, 53-54; 9, 2, 30, y T. C. Burgess, 1987, p. 187. Se aprecia el predominio del género epidíctico en los tipos de discurso mencionados por Teón, los cuales están comprendidos en los dos tratados de Menandro el Rétor sobre este género.

26 Theo, Prog., 117.
} 
futuro. ${ }^{27}$ Este plan es justificado por Nicolás, quien sugiere que la etopeya no debe ser argumentativa, ya que su objetivo es o agradar o conmover. ${ }^{28}$ Veremos en los textos que nos competen que tanto uno como otro tipo de elaboración es usado de manera indistinta, atendiendo más bien al plan y a los argumentos convenientes a cada una de las alocuciones.

En cuanto al estilo, solamente Aftonio y Nicolás dan consejos de cómo debe ser: el primero propone que sea claro, conciso, florido, suelto y sin figuras $;^{29}$ no obstante, el ejemplo de etopeya de Níobe que proporciona en su manual es de un estilo más bien complejo, ${ }^{30}$ el segundo, prescribe que se usen frases cortas con estilo natural y conciso para no restar emoción, pues quien está afectado no atiende al cuidado de la forma. ${ }^{31}$ Pareciera que prima el impacto que pueda causar la alocución por el pathos, aun pasando por encima de las normas, más que el ethos del personaje. Hermógenes se limita a afirmar que el estilo debe ser adecuado a los personajes propuestos, ${ }^{32}$ pero en su obra Sobre las formas de estilo detalla el modo en que cada estilo denota el carácter; ${ }^{33}$ y a la mujer, considerando el caso de Níobe, corresponde un estilo simple. ${ }^{34}$

Añádase también que las etopeyas de tipo patético requieren mayor habilidad por parte del predicador, pues Quintiliano

\footnotetext{
${ }^{27}$ Hermog., Prog., 21-22, Aphth., Prog., 35, Nicol., Prog., 65-66. También Men. $R h ., 413,15$ y 435, 16, aconseja la elaboración de los discursos de acuerdo a los tres tiempos.

${ }^{28}$ Nicol., Prog., 67.

${ }^{29}$ Aphth., Prog., 35. También Men. Rh., 374, 6, relaciona la prosopopeya con un estilo relajado. Sobre la claridad, cf. Hermog., Id., 227-241.

${ }^{30}$ Otro ejemplo en cuanto al estilo elaborado en la composición de una etopeya, en este caso epigráfica, lo hallamos analizado en el opúsculo de J. A. Fernández Delgado \& J. Ureña Bracero, 1991. Sobre las etopeyas hexamétricas conservadas en papiro y otros materiales, cf. J. A. Fernández Delgado, 1994, y R. Cribiore, 1996.

${ }^{31}$ Nicol., Prog., 66.

${ }^{32}$ Hermog., Prog., 22.

${ }^{33}$ Hermog., Id., 320-413.

${ }^{34}$ Ibidem, 323.
} 
juzga que conmover los afectos es la tarea propia del orador y se cuenta entre las cosas más difíciles de lograr. ${ }^{35}$ Piénsese que, a pesar de haber un lenguaje habitual de comunicación en una sociedad, debe elegirse la expresión y el vocabulario particular del personaje determinado ${ }^{36}$ en pro de la verosimilitud, de la que dependerá el éxito y la credibilidad de cualquier alocución dentro del discurso. La etopeya da al orador la oportunidad de mostrar otras dotes $;{ }^{37}$ a propósito de la enárgeia en relación con la prosopopeya Quintiliano aconseja:

Donde se hiciere necesario despertar compasión, creamos que nos ha sucedido a nosotros mismos lo que es objeto de nuestro lamento, y tratemos de llevar a nuestro corazón la persuasión debida. Seamos nosotros ahora esos hombres que han sufrido las violencias, las afrentas, las calamidades de que nos quejamos, $\mathrm{y}$ en el proceso no tratemos el caso como si hubiese ocurrido a persona ajena, sino que por un momento hagamos nuestro aquel dolor. Así diremos lo que habríamos de decir en un infortunio nuestro parecido. ${ }^{38}$

Por lo tanto, el ejercicio preparaba al futuro orador para la elaboración de discursos directos dentro de la declamación, aunque no era ésta su única utilización. Entre los géneros de discurso incluidos en la etopeya, Teón menciona los panegíricos, los exhortativos y los epistolares, ${ }^{39}$ a ello se añade el jui-

\footnotetext{
${ }^{35}$ Quint., Inst., 6, 2, 5.

${ }^{36}$ Sobre el lenguaje social y el privado, cf. P. Friedrich \& J. Redfield, 1978, pp. 263-265.

${ }^{37}$ Cf. Quint., Inst., 6, 2, 36, donde se alude a la práctica de la prosopopeya en la escuela como si de una clase de interpretación se tratase.

${ }^{38}$ Quint., Inst., 6, 2, 34. Acerca de la relación entre enárgeia y etopeya, cf. H. Lausberg, 1999, §§ 812, 817 y 820.

39 Theo, Prog., 115. Sobre la relación existente entre epístola y etopeya, cf. Demetr., Eloc., 227; Bas., EMax. phl. [9], EIov. com. [163] y EEpisc. [165]; J. Bompaire, 1958, pp. 295-297; J. Ureña Bracero, 1993 (con abundante bibliografía); H. Fruteau de Laclos, 1999, pp. 87-88; R. I. Gallé Cejudo, 1999, pp. 59-72, y P. A. Rosenmeyer, 2001.
} 
cio de Nicolás, quien afirma que además de ser la etopeya un ejercicio útil para la práctica del género epistolar, lo es para los tres tipos de discurso. ${ }^{40}$ Esto se comprobará por los distintos propósitos y las circunstancias en que Basilio introduce la alocución de tres de los personajes que intervienen en algunas de sus homilías (Homs. 19, 6 y 7): ${ }^{41}$ para demostrar, para deliberar o para reprobar, y comprobaremos que el de Cesarea sabe, al decir de Menandro, hacer "reconocer el carácter de un hombre a partir de sus palabras". ${ }^{42}$

Pocos son los personajes femeninos que hallamos en la obra de Basilio, entre ellos encontramos a la madre de uno de los mártires, la cual aparece hacia el final de la Homilia in $X L$ martyres sebastenses ( $P G 31,524 \mathrm{~B})$. Las palabras de la madre contribuyen a aumentar el pathos del martirio, por lo que nuevamente apreciamos que la situación es tomada del repertorio de los temas escolares: las palabras de una mujer ante un ser querido, en este caso, muy próximo a la muerte.

Después de la noche del martirio la mujer halla a su hijo aún con vida, por lo que los verdugos, creyendo que todavía podía salvar la vida si abjuraba, no lo llevaban a la pira como al resto de los mártires; y su propia madre lo insta a ir con las siguientes palabras: "Ve, hijo mío" - dijo-, "al feliz tránsito con tus compañeros, con tus camaradas. No seas privado de esa compañía, no comparezcas ante el Señor como inferior a los demás". ${ }^{43}$

La etopeya es anunciada por el verbo $\dot{\varepsilon} \varphi \theta \dot{\varepsilon} \gamma \xi \alpha \tau$, dramatizada por el apóstrofe $\hat{\omega} \pi \alpha \hat{\imath}$ y por la falta de conjunciones, que

\footnotetext{
${ }^{40}$ Nicol., Prog., 66-67.

${ }^{41}$ Traducción al español por la autora: M. A. Valdés García, Basilio de Cesarea. Panegíricos a los mártires. Homilías contra las pasiones, Madrid, Ciudad Nueva (Biblioteca de Patrística, 73), 2007.

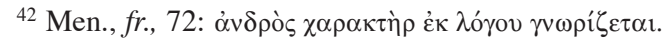

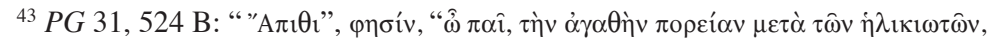

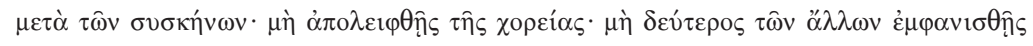
$\tau \hat{\text { ஸ̣ }} \Delta \varepsilon \sigma \pi$ ó
} 
ayudan a lograr un estilo afectado; es enfatizada además por un pnoív dentro de la alocución, la cual no habría causado el mismo efecto, si sus palabras hubieran sido referidas por Basilio de manera indirecta. Sobre la eficacia de la etopeya en los discursos dice Quintiliano:

El juez no tiene la impresión de oír a hombres que lloran desventuras ajenas, sino que está recogiendo en sus propios oídos el sentimiento y la voz de unos desgraciados, cuya muda contemplación provoca lágrimas; y cuánto más dignos de conmiseración son esos males, si ellos personalmente los exponen, tanto más aumentan en cierto grado su poder para hacer aflorar los sentimientos cuando se les escucha de su propia boca; igual que en los actores de teatro su misma palabra y su mismo recitado adquieren, bajo la máscara escénica, mayor eficacia para excitar los sentimientos. ${ }^{44}$

Es el personaje, el que, aun respondiendo a un nombre común, conmueve: una piadosa madre. El tipo de personaje, aunque anónimo, cumple las cualidades enumeradas por Aristóteles en su Poética para los caracteres, éstos deben ser: buenos, apropiados, semejantes, consecuentes, necesarios y verosímiles. ${ }^{45}$

Dentro de este progymnasma de brevedad obligada, según la preceptiva de Aftonio, ${ }^{46}$ hallamos, no obstante, el uso de la sinonimia, que refuerza el deseo de la madre de que los mártires realicen juntos el tránsito: “con tus compañeros, con tus camaradas" ( $\mu \varepsilon \tau \grave{\alpha} \tau \hat{\omega} v \dot{\eta} \lambda \iota \kappa \iota \omega \tau \hat{\omega} v, \mu \varepsilon \tau \grave{\alpha} \tau \hat{\omega} v \sigma v \sigma \kappa \eta \dot{v} v \omega)$.

\footnotetext{
${ }^{44}$ Quint., Inst., 6, 1, 26: "Non enim audire iudex uidetur aliena mala deflentis, sed sensum ac uocem auribus accipere miserorum, quorum etiam mutus aspectus lacrimas mouet: quantoque essent miserabiliora si ea dicerent ipsi, tanto sunt quadam portione ad adficiendum potentiora cum uelut ipsorum ore dicuntur, ut scaenicis actoribus eadem uox eademque pronuntiatio plus ad mouendos adfectus sub persona ualet".

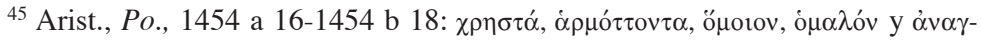

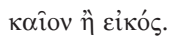

${ }^{46}$ Cf. Aphth., Prog., 35.
} 
Aunque se trata de una etopeya mixta, es mayormente emotiva, un rasgo al que contribuye forzosamente el tipo de personaje, en el que, al igual que el de la etopeya siguiente: un padre de familia, prima el pathos.

La angustia de un padre es la que nos relata Basilio en esta otra etopeya ubicada en su Homilia in illud: Destruam horrea mea et maiora aedificabo $25,10-22 .{ }^{47}$ Este pasaje ha sido considerado bajo distintos puntos de vista. Bernardi lo identifica con una ékphrasis, cosa no del todo inexacta, puesto que la etopeya en muchos casos proporciona viveza, una cualidad inherente a la descripción; ${ }^{48}$ y lo considera un típico "ejercicio de escuela". ${ }^{49}$ Para J. M. Campbell se trata de una prosopopeya, parte de una ékphrasis $;^{50}$ A. S. Dirking ve una synkrisis en el diálogo entre el hambre y el amor del padre, ${ }^{51}$ Y. Courtonne, editor y traductor de Basilio, lo clasifica como una narración de gran calidad retórica ${ }^{52}$ y C. Lo Cicero lo estima una prosopopeya dentro de un excursus. ${ }^{53}$ Tal variedad de opciones obliga a reflexionar sobre los estrechos límites, a menudo sutiles, que median entre los distintos ejercicios retóricos implicados.

Basilio pone en la mente de un infeliz padre la decisión que debe tomar en una situación extrema, vender a uno de sus hijos. ${ }^{54}$ Debemos notar que, de acuerdo con los consejos de

\footnotetext{
${ }^{47}$ Usamos para esta homilía la edición de Y. Courtonne, Saint Basile. Homélies sur la richesse, Paris, Firmin-Didot, 1935.

${ }^{48}$ Cf. Quint., Inst., 9, 2, 29.

${ }^{49}$ J. Bernardi, 1968, p. 63. A. Salvini, 1998, p. 852, también la considera una descripción.

50 J. M. Campbell, 1922, pp. 58 y 137-138 (etopeya y ékphrasis respectivamente).

${ }^{51}$ A. S. Dirking, 1911, p. 62. En cuanto reflexión también podría considerarse como diálogo interior, cf. M. F. Ferrini, 1990. A. Meredith, 1998, p. 95, lo considera parte de una synkrisis entre el rico y el pobre.

${ }^{52}$ Y. Courtonne, 1935, p. 119.

${ }^{53}$ C. Lo Cicero, 1983, p. 436. La etopeya, en sus distintas acepciones, es una forma de introducir excursus, cf. M. F. Ferrini, 1987-1988, p. 151.

${ }^{54}$ Sobre los niños vendidos como esclavos, cf. Bas., HPs. 14b (PG 29, 277 B). Lib., Or., 46, 23 refiere la venta de los hijos para el pago de deudas. Ambros., Nab. (PL 14, 772 A-773 B) amplifica una situación semejante.
} 
Teón, "antes que nada es preciso reflexionar sobre cuál es el carácter propio de la persona que habla"; los rétores insisten en que la etopeya debe ser adecuada al personaje:

Debemos proporcionar a cada uno de los hechos la elocución adecuada, buscando al mismo tiempo lo que cuadra bien al personaje, al modo, al tiempo, a la fortuna y a cada uno de los elementos antes mencionados. ${ }^{55}$

La etopeya elaborada por Basilio es apropiada al personaje, pues según Teón "éste es sobre todo un ejercicio expositivo de caracteres y emociones". ${ }^{56}$ Siguiendo a Hermógenes, esta etopeya se clasificaría como $\dot{\alpha} \pi \lambda \eta ́$ y $\mu \iota \kappa \tau \eta{ }^{57}$ Es simple porque el padre delibera consigo mismo; mixta porque, usando palabras del mismo Hermógenes, es "una mezcla de $\hat{\eta} \theta$ o y $\pi \dot{\alpha} \theta$ o $\varsigma$ ", 58 aunque parece predominar el pathos. En cuanto a su estilo, como sugiere Aftonio, es claro y conciso. ${ }^{59}$

No obstante que, según los teóricos, una etopeya anuncia su carácter ficticio mediante el optativo, ${ }^{60}$ Basilio usa sin más un

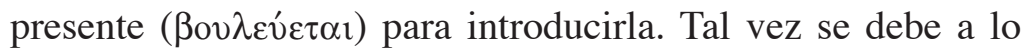
común de una circunstancia así en tiempos del imperio, lo que la convierte en un discurso posible, y, por qué no, incluso real. El orador busca lograr seguramente un compromiso moral de parte de la audiencia al introducir la reflexión de ese modo,

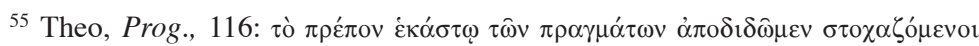

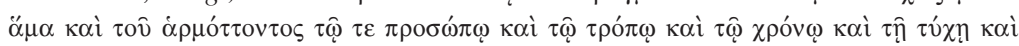
$\dot{\varepsilon} \kappa \alpha ́ \sigma \tau \omega \tau \hat{\omega} \nu \pi \rho \circ \varepsilon 1 \rho \eta \mu \varepsilon ́ v \omega \nu$.

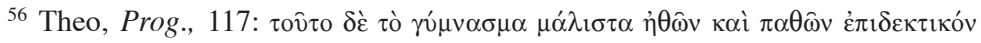

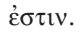

${ }^{57}$ Hermog., Prog., 20-21.

${ }^{58}$ Ibidem.

${ }^{59}$ Aphth., Prog., 35. Las figuras retóricas contenidas en este pasaje han sido

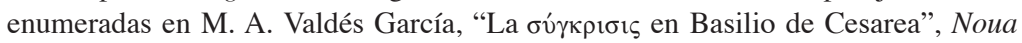
tellus, 25, 1, 2007, pp. 254-257.

${ }^{60}$ Recordemos que la fórmula introductoria más común para este progymnasma

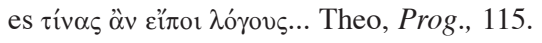


manteniendo el procedimiento etopéyico; de hecho, la pregunta con que comienza el discurso del personaje introduce la alocución siguiendo la preceptiva de los manuales y despierta en la asamblea el planteamiento anticipado de la disertación: "¿Qué cosas medita este padre?"61

La sucesión de preguntas y la alternancia de las respuestas expresan claramente los razonamientos contrapuestos que el padre se plantea ante tal dilema, y acentúan el dramatismo de la situación. Tan descorazonadora escena es introducida por Basilio con una breve narración en la que adelanta en parte la argumentación de que se servirá:

Contempla ahora el combate entre la tortura del hambre y los sentimientos paternos: aquélla lo amenza con la muerte más terrible, pero la naturaleza lo retiene persuadiéndolo de morir con sus hijos. Cuantas veces se resuelve, otras tantas se arrepiente. Finalmente sucumbe forzado por la necesiadad y la implacable miseria. ${ }^{62}$

Para la alocución usa los dos tipos de argumentación sugeridos por los rétores, la relativa a las tesis prácticas: ${ }^{63}$

“¿Acudiré al mayor?” es vergonzoso: "Pero me avergüenzo por su primogenitura".

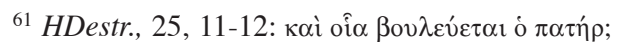

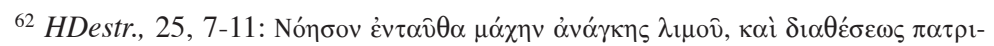

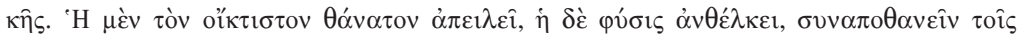

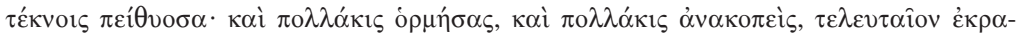

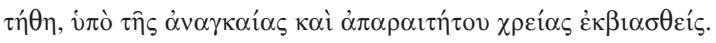

${ }^{63}$ Theo, Prog., 118 (la cursiva indica los lugares de argumentación). En el apartado de la prosopopeya Teón mismo remite a las fuentes de argumentación de

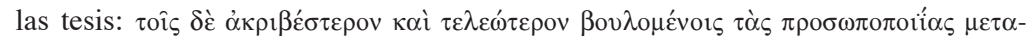

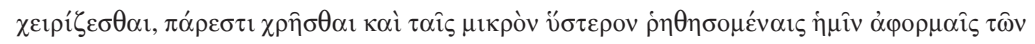

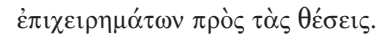

Theo, Prog., 120, dentro de la exposición de la thesis establece la diferen-

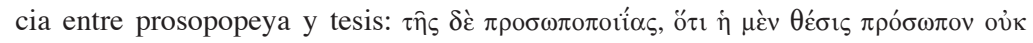

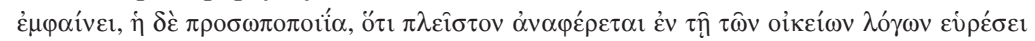

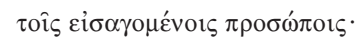


“¿O al más pequeño?” goza de consideración: "Pero siento pena de su edad, ignorante de los sufrimientos".

no es fácil: “¿Qué haré? ¿A cuál de ellos he de faltar?"

no está de acuerdo a la naturaleza y las costumbres: "¿Qué instinto bestial asumiré? ¿Cómo podré olvidar mi naturaleza?"

y la recomendada por Hermógenes:

La elaboración discurrirá por los tres ejes temporales comenzando por el presente, diciendo que es difícil; luego retrocediendo al pasado, diciendo que era partícipe de mucha felicidad; a continuación has de pasar al futuro, diciendo que lo que sobrevendrá será mucho más terrible. ${ }^{64}$

El salto de un tiempo verbal a otro pone de manifiesto la confusión, la duda y la angustia del padre, que considera en todo momento las consecuencias de su decisión. Evidentemente predomina el futuro, pues es el tiempo propio de la deliberación: ${ }^{65}$

Si los conservo a todos, a todos los veré consumidos por el sufrimiento; si vendo a uno, ¿con qué ojos miraré a los demás, si ya soy para ellos objeto de desconfianza? ¿Cómo viviré en mi casa, si yo mismo me he privado de mi hijo? ¿Cómo sentarme a una mesa cuya abundancia tiene semejante precio? ${ }^{66}$

El objetivo de todo orador es convencer. Es comprensible que Basilio hubiera decidido introducir en su homilía contra la ri-

${ }^{64}$ Hermog., Prog., 21-22.

${ }^{65}$ Arist., Rh., 1358 b 14.

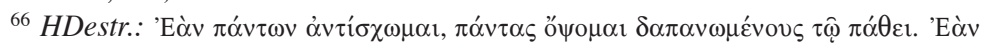

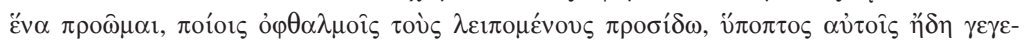

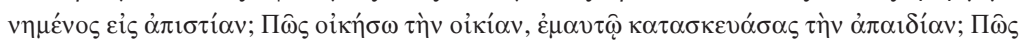

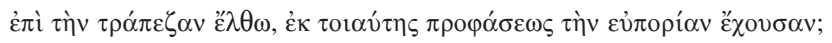


queza esta etopeya como una reflexión en silencio debido a la gravedad del asunto. ${ }^{67} \mathrm{El}$ uso del diálogo consigo mismo implica al oyente en el discurso de manera más patente, pues le supone situarse en el lugar del personaje aludido, en su situación y con sus sentimientos; gracias a ello se produce la enárgeia. ${ }^{68} \mathrm{El}$ propósito de este discurso irreal dentro de una situación real era concienciar a las clases altas de la sociedad imperial.

El siguiente pasaje contenido en la homilía de Basilio Contra la riqueza (HDiv. 71, 1-7), presenta una etopeya doble pronunciada por los criados del rico que acaba de morir; la alocución confiere enárgeia y, por lo tanto, verosimilitud a la descripción de las circunstancias en el momento de la muerte. Ellos discuten ( $\kappa \alpha \tau \alpha \varphi \imath \lambda о \sigma o \varphi \eta ́ \sigma o v \sigma \imath)$ entre sí lo que consideran

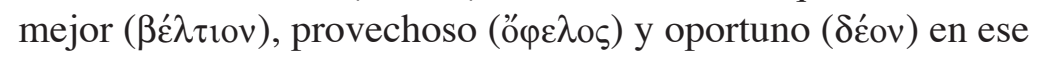
momento, por ello es visible que la elaboración de la etopeya se hace mediante el método de argumentación, siguiendo la preceptiva expuesta por Teón: ${ }^{69}$

Es una vulgaridad, dirán, adornar a un muerto y transportar suntuosamente al que ya ni siente. ¿No es mejor que se adornen los que viven con el costoso y el espléndido traje, que dejar que se pudra junto con el muerto? ¿Qué le aprovecha un sepulcro suntuoso, un entierro fastuoso y un gasto inútil? Es más oportuno utilizarlo en las necesidades diarias de los que se quedan. ${ }^{70}$

En cierto sentido también vemos en estos personajes el reflejo del amo; él era avaro y sus criados terminan deliberando y

\footnotetext{
${ }^{67}$ M. Brioso Sánchez, 1999, pp. 158-159, considera que el monólogo como reflexión con uno mismo se introduce en momentos decisivos, aptos para la exploración psicológica o para suscitar emotividad.

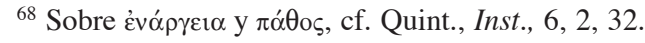

${ }^{69}$ Theo, Prog., 118.

${ }^{70}$ Bas., HDiv., 71, 1-7.
} 
procediendo del modo que lo hubiera hecho él, lo cual justificaría su modo de actuar, incluso ante sus propios ojos y siendo él mismo el afectado. Apreciamos que el tema de la predicación contra la avaricia y la caracterización de los personajes interactúan de forma tan íntima que prácticamente se fusionan ambas cosas.

Especialmente las etopeyas que son introducidas y termina-

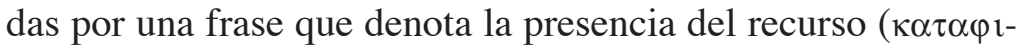

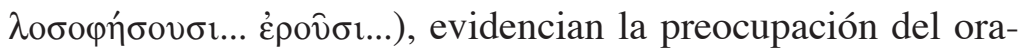
dor por dejar clara la transición de un tema o argumento a otro. Muchas veces, debido a que son comenzadas y concluidas de manera tan precisa, dichas partes podrían quedar del todo exentas.

\section{Conclusión}

Dentro de la obra de Basilio hallamos en su epístola 163, una alusión al recurso de la etopeya; reproducimos la cita en la que habla sobre la definición del carácter a través de la palabra:

He visto tu alma en tu carta. Y, en verdad, ni un pintor puede comprender tan exactamente el carácter de una persona como la palabra puede retratar los secretos del alma. Pues, cuando la expresión en tu carta nos perfila adecuadamente lo cuidado de tu carácter, lo genuino de tu valor y lo oportuno de tu mente en todo, también nos proporciona gran consuelo por tu ausencia. ${ }^{71}$

Observamos entonces que las palabras pueden sustituir de alguna manera a la persona ausente o a su pensamiento, por lo que la etopeya debe ser usada con habilidad y en el momento

\footnotetext{
${ }^{71}$ Bas., EIov. com. [163], 1, 1-7. En la EMax. phl. [9], 1 Basilio afirma: Eỉóves

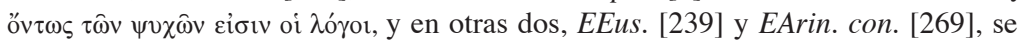
refiere a la comunicación por correspondencia como "conversación por carta".
} 
oportuno. Apreciamos, en principio, que el uso de esta figura a lo largo de la obra de Basilio es regular.

Por lo destacado de este procedimiento, la etopeya debía de ser usada no muy constantemente, sino solamente en las partes donde se quisiera acentuar una situación determinada para convencer, en el caso de las etopeyas morales, o para conmover, en el caso de las preferentemente emotivas; pero en Basilio predominan las etopeyas mixtas, puesto que así se complementa la intención moralizadora con el adfectus.

El uso de emociones $(\pi \dot{\alpha} \theta \eta)$ y caracteres $(\hat{\eta} \theta \eta)$ es primordial al establecer un diálogo retórico o un debate imaginario, que permite al autor argumentar un mismo asunto bajo diversos aspectos y, así, confirmar sus premisas o refutarlas, llamando la atención sobre distintos ángulos para no hacer monótona su predicación, a la vez que le son útiles como transición entre un argumento y otro.

Las tres alocuciones que hemos analizado son elementos de composición de sendas ékphraseis, ambos recursos - etopeya y descripción-, en cierto modo se complementan. ${ }^{72}$ Si la ékphrasis nos proporciona la descripción de las circunstancias en que se encuentra el personaje y de su apariencia física; la etopeya, como algunos afirman, puede considerarse un retrato moral ${ }^{73}$ que a menudo facilita el conocimiento de los valores $y$, muchas veces, incluso, del estado emocional del personaje, por lo que ambos progymnásmata colaboran en la caracterización de los individuos. Así se conjuntan el plano objetivo de la descripción con el subjetivo de la etopeya, si bien estos aspectos son más

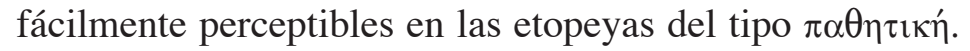

En los ejemplos vistos, el propósito de Basilio es, ante todo, conseguir la viveza o enárgeia, cuyo objetivo es lograr la adhesión del auditorio al pensamiento del orador a través del de los distintos personajes.

\footnotetext{
${ }^{72}$ Cf. Nicol., Prog., 69 y 71.

${ }^{73}$ Cf. J. C. Fredouille, 1972, pp. 38-49.
} 


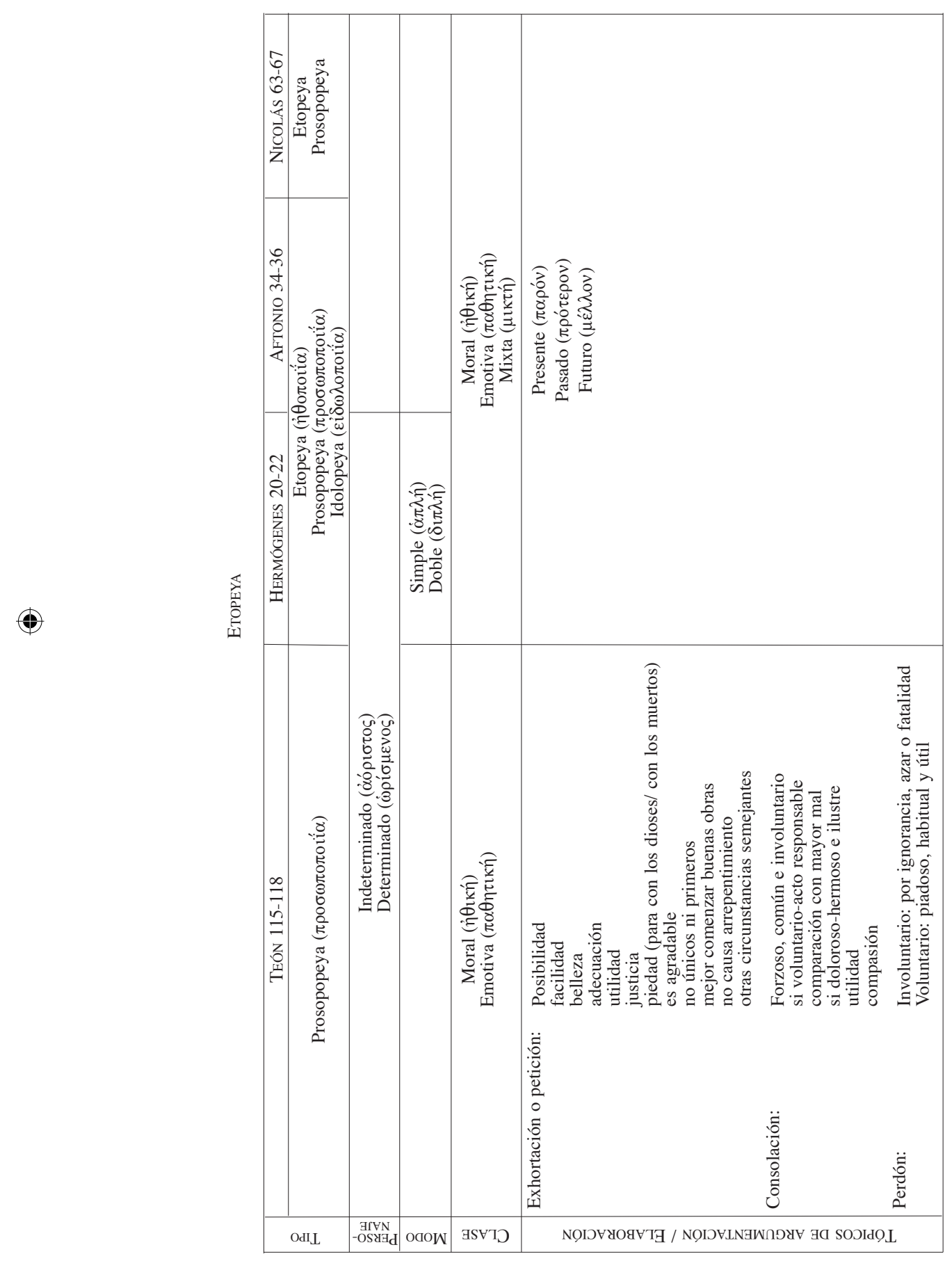




\section{BIBLIOGRAFÍA}

Amato, E., \& J. Schamp (eds.), Hthopoiia. La representation de caractères entre fiction scolaire et réalité vivante à l'époque imperiale et tardive, Salerno, Helios Editrice, 2005.

Bernardi, J., La prédication des Péres cappadociens, Paris, Presses Universitaires de France, 1968.

Blondell, R., The Play of Character in Plato's Dialogues, Cambridge, CUP, 2004.

Bompaire, J., Lucien Ecrivain. Imitation et Creation, Paris, De Boccard, 1958.

Brioso SÁnchez, M., “Aspectos del estilo directo en la novela griega antigua”, Habis, 30, 1999, pp. 153-173.

BurgESS, T. C., "Epideictic Literature", $C P h, 3,1902$, pp. 89-261 (reimpr. N. Y., Garland, 1987).

Campbell, J. M., The Influence of the Second Sophistic on the Style of the Sermons of St. Basil, Washington, Kessinger Publishing Company, 1922.

Courtonne, Y., Saint Basile. Homélies sur la richesse, Paris, Firmin-Didot, 1935.

CRIBIORE, R., Writing, Teachers and Students in Graeco-Roman Egypt, Atlanta, Scholars Press, 1996.

DIRKING, A. S., Basilii Magni de divitiis et paupertate quam habeant rationem cum veterum philosophorum doctrina, Münster, Typographia Aschendorffiana, 1911,

Felten, I. (ed.), Nicolaus. Progymnasmata (Rhetores Graeci), vol. 11, Lipsiae, Teubner, 1913.

FERnÁndez Delgado, J. A., "Hexametrische-ethopoiiai auf Papyrus und anderen Materialen", A. Bülow-Jacobsen (ed.), Proceedings of the XX International Congress of Papyrologists, Copenhague, Museum Tusculanum Press, 1994, pp. 299-305.

- , \& J. UREÑA BRACERO, Un testimonio de la educación literaria griega en época romana: IG XIV 2012 = Kaibel, EG 618, Cáceres, Universidad de Extremadura, 1991.

FERrini, M. F., "Le parole e il personaggio: Monologhi nel Romanzo Greco", GIF, 42, 1990, pp. 78-82.

- "Achille Tazio V, 25-27. Analisi di un discorso diretto nel romanzo greco", AION (filol.), 9-10, 1987-1988, pp. 151-171.

Fournet, J. L., "Une éthopée de Caïn dans le Codex des Visions de la Fondation Bodmer”, ZPE, 92, 1992, pp. 253-266. 
Fredouille, J. C., Tertullien et la conversion de la culture antique, Paris, Études Agustiniennes, 1972.

Friedrich, P., \& J. Redfield, "Speech as a Personality Symbol: The Case of Achilles", Language, 54, 1978, pp. 263-288.

Fruteau de LaClos, H., Les progymnasmata de Nicolaos de Myra dans la tradition versicolore des exercises preparatoires de rhetorique, Lille, Atelier National de reproduction des thèses, 1999.

Gallé Cejudo, R. I., Aristéneto. Cartas eróticas, Madrid, Ediciones Clásicas, 1999.

GonzÁlez Equinua, R., La etopeya en las Etiópicas de Heliodoro, trabajo de grado, Universidad de Salamanca, 2007.

Jong, I. J. F. de, "The Voice of Anonymity: tis-Speeches in the Iliad", Eranos, 85, 1987, pp. 69-84.

Kraus, M., "Rehearsing the Other Sex: Impersonation of Women in Ancient Classroom Ethopoeia", J. A. Fernández Delgado, F. Pordomingo y A. Stramaglia (eds.), Escuela y Literatura en Grecia antigua, Cassino, Università di Cassino, 2007, pp. 455-468.

Kustas, G. L., "The Function and Evolution of Byzantine Rhetoric", Viator, 1, 1970, 55-73 (reimpr. G. Nagy [ed.], Greek Literature, vol. 9, New York, Routledge, 2001, pp. 179-197).

Lausberg, H., Manual de retórica literaria, 3 vols., trad. J. Pérez Riesco, Madrid, Gredos, 1999.

Lo Cicero, C., "La struttura delle omelie sulla ricchezza di Basilio", AA.VV., Basilio di Cesarea, la sua età e il Basilianesimo in Sicilia Atti del Congresso Internazionale 3-6 XII, 1979, vol. 2, Messina, Centro di Studi Umanistici, 1983, pp. 425-487.

Meredith, A., "The Three Cappadocians On Beneficence", M. B. Cunningham (ed.), Preacher and Audience: Studies in Early Christian and Byzantine Homiletics, Leiden, Brill, 1998, pp. 89-104.

Ortega Carmona, A., Quintiliano de Calahorra. Sobre la formación del orador, 5 vols., Salamanca, Universidad Pontificia de Salamanca, 1997-2001.

Patillon, M.-G. Bolognesi (eds.), Aelius Theo, Progymnasmata, Paris, Belles Lettres, 1997.

Perelman, Ch., \& L. Olbrechts-Tyteca, Tratado de la argumentación: La nueva retórica, trad. de J. Sevilla Muñoz, Madrid, Gredos, $2000^{5}$.

Pérez Custodio, M. V., "La expresión del ethos y el pathos en las etopeyas escolares del Renacimiento", J. M. Maestre Maestre, J. P. Barea \& L. Charlo Brea (eds.), Humanismo y Pervivencia del Mundo Clásico II. Homenaje al profesor Luis Gil, vol. 2, Cádiz, Universidad de Cádiz, 1997, pp. 795-806. 
Rabe, H. (ed.), Hermogenes. Progymnasmata, Rhetores Graeci (RG), vol. 6, Lipsiae, Teubner, 1913.

- (ed.), Aphthonius. Progymnasmata, RG, vol. 10, Lipsiae, Teubner, 1926.

Reche Martínez, Ma. D., Teón, Hermógenes, Aftonio. Ejercicios preparatorios, Madrid, Gredos (Biblioteca Clásica Gredos, 158), 1991.

Rosenmeyer, P. A., Ancient Epistolary Fictions, Cambridge, CUP, 2001.

SAlvin, A., "Sulla tecnica di traduzione dal greco in latino nelle Homiliae Morales di Basilio-Rufino", SCO, 46, 1998, pp. 845-889.

STOWERS, S. К., “Apostrophe, ПРОГЛПОПОІІА and Paul's Rhetorical Education”, J. T. Fitzgerald, Th. H. Olbricht \& L. M. White (eds.), Early Christianity and Classical Culture, Leiden, Brill, 2003, pp. 351369.

UREÑa Bracero, J., "Etopeya y caracterización en escolios y comentarios homéricos", $A E F, 23,2000$, pp. 453-469.

-, "La carta ficticia griega: Los nombres de personajes y el uso del encabezamiento en Alcifrón, Aristeneto y Teofilacto", Emérita, 61, 1993, pp. 267-298. 